\title{
Patients with Parkinson's disease need spiritual care
}

\author{
Piret Paal, Stefan Lorenzl \\ Palliative Care Research Hub, the Institute of Nursing Science and Practice, Paracelsus Medical University, Salzburg, Austria \\ Correspondence to: Piret Paal, PhD. Palliative Care Research Hub, the Institute of Nursing Science and Practice, Paracelsus Medical University, \\ Strubergasse 21, Salzburg A-5020, Austria. Email: piret.paal@pmu.ac.at. \\ Provenance and Peer Review: This article was commissioned by the Editorial Office, Annals of Palliative Medicine. The article did not undergo external \\ peer review. \\ Comment on: Prizer LP, Kluger BM, Sillau S, et al. Correlates of spiritual wellbeing in persons living with Parkinson disease. Ann Palliat Med \\ 2020;9:S16-23.
}

Submitted Nov 07, 2019. Accepted for publication Nov 30, 2019.

doi: 10.21037/apm.2019.11.24

View this article at: http://dx.doi.org/10.21037/apm.2019.11.24

In his bestselling book "Being Mortal: Medicine and What Matters in the End" the American surgeon Atul Gawande wrote: "The battle of being mortal is the battle to maintain the integrity of one's life - to avoid becoming so diminished or dissipated or subjugated that who you are becomes disconnected from who you were or who you want to be." (1). In palliative care, improving the spiritual dimension of whole person care has been merely an attempt to diminish the feeling of disconnectedness in self(-perception) of the most vulnerable. Attention to spirituality in patients' with chronic neurological diseases has been remarkably low. Today when palliative care capacity building among all healthcare practitioners caring for patients with chronic illnesses is increasing, and the demand towards maintaining the healthrelated quality of life has to be met, the interest towards why and how to tap into patients' and their caregivers' spiritual needs and resources is growing.

\section{Benchmarks in health-related spirituality}

In the 1960s, the UK hospice movement enriched medicine with the notion of spirituality as an important aspect of the total pain concept. Nurse, social worker and physician Dame Cecil Saunders fought for cancer patients' integrity uniting the best care practices from nursing and medicine and developing an ars moriendi model maintaining pain relief through ample dosing of morphine (2). Decades later, in 1991, the World Health Organization (WHO) provided the definition below for spiritual dimension.

"The spiritual dimension is understood to imply a phenomenon that is not material in nature, but belongs to the realm of ideas, beliefs, values and ethics that have arisen in the minds and conscience of human beings, particularly ennobling ideas. [...] The spiritual dimension plays a great role in motivating people's achievement in all aspects of life" (3).

The WHO's definition indicates that the spiritual dimension is an integral meaning-giving aspect of human existence, and thus, spiritual needs are universally experienced by healthcare professionals, patients and caregivers, particularly during critical and transformative life events. Since 1991, international efforts have been made to improve spiritual care not only in palliative care, but also in healthcare in general (4). In 1996, spiritual suffering and distress were listed at the NANDA nursing diagnosis guidelines (5). In 2006, WHO endorsed spirituality as a health-related quality of life indicator (6). In 2012, the International Council of Nurses (ICN) stated that "in providing care, the nurse promotes an environment in which the human rights, values, customs and spiritual beliefs of the individual, family and community are respected." (7). Despite all the efforts, healthcare professionals still report difficulty in grasping what is meant by spirituality and spiritual care, and hence, often fail to meet the spiritual needs of patients and caregivers $(8,9)$. In a review of European literature, Gijsberts et al. [2019] found that spiritual care in palliative care was seen as "attention for spirituality, presence, empowerment, and bringing peace" (10). The overall problem is that spirituality is rarely promoted as an integral component of health and well-being in public health and/ or patient education context, which means that patients and caregivers are equally confused when healthcare professionals (often unexpectedly) address their liberty 
to express spiritual topics in the secularized context of technical medicine $(11,12)$.

\section{Conceptualization attempts}

In most cases, patients and caregivers do not speak about their concerns and needs using the term spirituality. When asked about spirituality the oldest of old $(85+)$ from Sweden called it "something wonderful and incomprebensible" (13). Spirituality is a theoretical concept and the complexity of grasping what is meant by spirituality lays in acknowledging and accepting its broadness and uniqueness. The consensusbased definition from the United States defines spirituality as "the aspect of humanity that refers to the way individuals seek and express meaning and purpose and the way they experience their connectedness to the moment, to self, to others, to nature, and to the significant or sacred." (14). European palliative care operates according to the following working definition: "Spirituality is the dynamic dimension of human life that relates to the way people (individual and community) experience, express and/or seek meaning, purpose and transcendence, and the way they connect to the moment, to self, to others, to nature, to the significant and/or the sacred. Spirituality is multidimensional, consisting of

(I) Existential challenges (e.g., questions concerning identity, meaning, suffering and death, guilt and shame, reconciliation and forgiveness, freedom and responsibility, hope and despair, love and joy).

(II) Value based considerations and attitudes (what is most important for each person, such as relations to oneself, family, friends, work, things nature, art and culture, ethics and morals, and life itself).

(III) Religious considerations and foundations (faith, beliefs and practices, the relationship with God or the ultimate). However, it is critical to comprehend that in care situations it is the patient who tells us the form their own spirituality takes." (15).

In clinical practice spiritual care is entirely built on connectedness. Swinton and Pattison [2010] have pronounced that "the activity of 'spiritual care' or responding to 'spiritual need' becomes a matter of recognizing what people fail to receive in bealthcare contexts and trying to ensure that they are, as far as possible, assisted on their multiple quests to make that which may be absent present." (16).

\section{Connectedness is not an intervention}

In human existence, the whole is more than the sum of its parts, which means that human perception cannot be divided into physical, social, psychological or spiritual realms. Understanding the integrated nature of spirituality in all aspects of healthcare provision is crucial when speaking about disease induced failure in perception of self, others and the world. Even if overall perception and sense-making become challenged, seeking for meaning, negotiating the life-events, and constructing social-lives will be ongoing (17). Atul Gawande [2014] criticizes the one-dimensionality in medicine as follows: "Measurements of people's minute-by-minute levels of pleasure and pain miss this fundamental aspect of human existence. A seemingly happy life may be empty. A seemingly difficult life may be devoted to a great cause. We have purposes larger than ourselves. Unlike your experiencing self-which is absorbed in the momentyour remembering self is attempting to recognize not only the peaks of joy and valleys of misery but also bow the story works out as a whole." (1). Therefore, building and maintaining relationships to address and assist on receiving what people feel lacking is of utmost importance.

Spiritual care is defined as a generic health care function equivalent to emotional care or physical care and thus is not discipline specific (18). This means that all healthcare professionals carry the responsibility for spiritual care provision and maintaining the connectedness. Healthcare providers acknowledge the importance of spiritual care, yet, what is involved in providing the care remains unclear (19). Help is sought from developing assessment-tools (20) and the instrumentalisation of spiritual care. Patients, however, do not emphasize a need for specific spiritual interventions, most of them express their gratitude for feeling listened to as a 'whole being' instead (21).

\section{Healthcare chaplaincy}

Historically, but often also today, the terms "spiritual care", "pastoral care", and "chaplaincy care" have been used interchangeably, causing confusion and lack of precision (18). Compared to generic, not discipline specific spiritual care, healthcare chaplains, spiritual counselors and spiritual champions are seen as spiritual care specialists. Their role and competencies depend on many external factors, including organisational culture, different countries' political and religious histories, and/or available resources. In their books, Gordon J. Hilsman (22) and Steve Nolan (23) provide an educative and inspiring insight into the role of chaplains. Educational interventions involving chaplains increase the utilization of chaplain services $(12,24)$. 
As a healthcare innovator, the Mayo Clinic has launched a chaplain-led spiritual legacy pilot study "Hear My Voice" for patients with advanced diseases, including participants with progressive neurologic conditions (25). Although the results are yet to be published, the uniqueness of patient's spiritual legacies is nevertheless thought-provoking (and heart-breaking).

\section{The spirituality of patients with Parkinson's disease (PD)}

The study of Prizer et al. [2019] in the current issue of Annals of Palliative Medicine concludes that PD patients with a caregiver had significantly higher spiritual well-being (106.90, SD $=316.00)$ than participants without caregivers (78.49, SD =316.00). In these patients higher FACIT-Sp scores were associated with less impairment in quality of life, fewer non-motor symptoms, and reduced palliative care symptoms. Accordingly, the authors are demonstrating that "spirituality might be more important at an earlier stage of PD". Patients' spiritual well-being was associated with less anxiety and depression, which led to a conclusion "that spiritual counseling might be an important target in the management of $P D$ and should be considered when a patient and the caregiver are visiting our department" (26). In fact, this is one of the first comprehensive studies on this important dimension on human being in PD.

Results of the study by Prizer et al. [2019] highlight the influences of spirituality in PD management. Particularly the relationship between meaning, peace, faith, mood, palliative symptoms, and quality of life give reason to integrate spirituality in the clinical history obtained by the physician. Boersma et al. [2016] have demonstrated that at the time of diagnosis PD patients do not think that palliative care might be adequate for them. They believe that palliative care is associated with hospice, advanced cancer, and end of life. At the same time, many PD patients believe that religion and spirituality are important for them helping with the acceptance of PD diagnosis and for moving forwards in their new life with the disease (27).

Palliative care concepts for PD patients often include spirituality (28). In our own study, we found PD patients at the end of life in a state of tranquility, which addressed the caregiver's and our own sense of spirituality (29). Accordingly, all clinicians treating individuals with PD should consider spirituality in their practice and provide access to specialist spiritual care. This data further supports the effects of holistic, interdisciplinary care provided to PD patients by healthcare teams.

\section{Thinking of future benchmarks}

Liefbroer et al. [2019] have argued that integrating spiritual care into healthcare, which is spiritually diverse context, is challenging. Currently there are different perspectives regarding integrating the spiritual domain into healthcare and medicine. Here, two questions play a central role: (I) who should provide spiritual care? and (II) what is the role of caregivers' spirituality when providing spiritual care? (30). Gijsberts et al. [2019] found that in terms of conducting studies there seems to be a disagreement between NorthAmerican scholars who call for a hypothesis-driven outcome research based on the use of validated instruments and assessment of potential confounding variables (31). At the same time European researchers feel that healthrelated quality of life may not fully capture the effects of creative, narrative, or ritual work, which are forms of spiritual care provided. Accordingly, the suggested direction is the development of (instruments to measure) narrative outcomes (10). Everything considered, addressing and attending spirituality in patients' with chronic neurological diseases remain a challenge for clinicians and researchers. Patients with PD and their caregivers need spiritual care to make sense, seek for meaning, feel connected. Appropriate models of spiritual care, however, are yet to be developed.

\section{Acknowledgments}

Funding: None.

\section{Footnote}

Conflicts of Interest: The authors have no conflicts of interest to declare.

Ethical Statement: The authors are accountable for all aspects of the work in ensuring that questions related to the accuracy or integrity of any part of the work are appropriately investigated and resolved.

Open Access Statement: This is an Open Access article distributed in accordance with the Creative Commons Attribution-NonCommercial-NoDerivs 4.0 International License (CC BY-NC-ND 4.0), which permits the noncommercial replication and distribution of the article with the strict proviso that no changes or edits are made and the 
original work is properly cited (including links to both the formal publication through the relevant DOI and the license). See: https://creativecommons.org/licenses/by-nc-nd/4.0/.

\section{References}

1. Gawande A. Being Mortal: Medicine and What Matters in the End. London: Profile Books; 2014.

2. Porter R. The Greatest Benefit to the Mankind: A Medical History of Humanity from Antiquity to the Present. Los Angeles: Fontana Press; 1999.

3. World Health Organization. The Spiritual Dimension. (1991) Issue 9290211407; Chapter 4. Available online: http://www.worldebooklibrary.org/wplbn0000152153world-he alth-organization-publication-year-1991issue-9290211407-chapter-26-by-world-healthorganization.aspx?

4. Puchalski CM, Vitillo R, Hull SK, et al. Improving the spiritual dimension of whole person care: reaching national and international consensus. J Palliat Med 2014;17:642-56.

5. NANDA. Spiritual suffering. Spiritual Distress. 1996. Available online: http://www.nandanursingdiagnosislist. org/functional-health-patterns/spiritual-suffering/

6. WHOQOL SRPB Group. A cross-cultural study of spirituality, religion, and personal beliefs as components of quality of life. Soc Sci Med 2006;62:1486-97.

7. International Council of Nurses. The ICN Code of Ethics for Nurses. In: Geneva ICoN, editor. Switzerland 2012 .

8. van der Weegen $\mathrm{K}$, Hoondert M, Timmermann M, et al. Ritualization as Alternative Approach to the Spiritual Dimension of Palliative Care: A Concept Analysis. J Relig Health 2019;58:2036-46.

9. Appleby A, Swinton J, Bradbury I, et al. GPs and spiritual care: signed up or souled out? A quantitative analysis of GP trainers' understanding and application of the concept of spirituality. Educ Prim Care 2018;29:367-75.

10. Gijsberts MHE, Liefbroer AI, Otten R, et al. Spiritual Care in Palliative Care: A Systematic Review of the Recent European Literature. Med Sci (Basel) 2019. doi: 10.3390/ medsci7020025.

11. Paal P, Frick E, Roser T, et al. Expert Discussion on Taking a Spiritual History. J Palliat Care 2017;32:19-25.

12. Soroka JT, Collins L, Creech G, et al. Spiritual Care at the End of Life: Does Educational Intervention Focused on a Broad Definition of Spirituality Increase Utilization of Chaplain Spiritual Support in Hospice? J Palliat Med 2019;22:939-44.
13. Norberg C, Santamäki-Fischer R, Isaaksson, U, et al. Something wonderful and incomprehensible: Expressions and experiences of spirituality among very old people. J. Study Spiritual 2019;9:125-37.

14. Puchalski C, Ferrell B, Virani R, et al. Improving the Quality of Spiritual Care as a Dimension of Palliative Care: The Report of the Consensus Conference. J Palliat Med 2009;12:885-904.

15. Nolan S, Saltmarsh P, Leget CJW. Spiritual care in palliative care. Eur J Pall Care 2011:86-9.

16. Swinton J, Pattison S. Moving beyond clarity: towards a thin, vague, and useful understanding of spirituality in nursing care. Nurs Philos 2010;11:226-37.

17. Paal P. Narrative Encounters in the End of Life Care. In: Asplund C. editor. The Therapeutic Uses of Storytelling. Lund: Nordic Academic Press; 2013:159-79.

18. Handzo G. Spiritual Care for Palliative Patients. Curr Probl Cancer 2011;35:365-71.

19. Bursell J, Mayers CA. Spirituality within Dementia Care: Perceptions of Health Professionals. Br J Occupational Therapy 2010;73:144-51.

20. Monod S, Brennan M, Rochat E, et al. Instruments Measuring Spirituality in Clinical Research: A Systematic Review. J Gen Intern Med 2011;26:1345.

21. Pujol N, Leboul D, Prodhomme C, et al. Is Spiritual Care the Hospital's Business? A Qualitative Study on Patients' Preferences About the Integration of Spirituality in Palliative Care Units (PCU). J Pain Symptom Manage 2018;56:e47-8.

22. Hilsman GJ. Spiritual Care in Common Terms: How Chaplains Can Effectively Describe the Spiritual Needs of Patients in Medical Records. London \& Philadelphia: Jessica Kingsley Publishers; 2016.

23. Nolan S. Spiritual Care at the End of Life: The Chaplain as a 'Hopeful Presence'. London \& Philadelphia: Jessica Kingsley Publishers; 2011.

24. Paal P, Helo Y, Frick E. Spiritual Care Training Provided to Healthcare Professionals: A Systematic Review. J Pastoral Care Counsel 2015;69:19-30.

25. Mayo Clinic. Hear My Voice: A Chaplain-Led Spiritual Legacy Pilot Study for Patients with Advanced Diseases 2018. Available online: https://www.mayo.edu/research/ clinical-trials/cls-20313727\#overview

26. Prizer LP, Kluger BM, Sillau S, et al. Correlates of spiritual wellbeing in persons living with Parkinson disease. Ann Palliat Med 2020;9:S16-23.

27. Boersma I, Jones J, Carter J, et al. Parkinson disease patients' perspectives on palliative care needs: What are 
they telling us? Neurol Clin Pract 2016;6:209-19.

28. Kluger BM, Shattuck J, Berk J, et al. Defining Palliative Care Needs in Parkinson's Disease. Mov Disord Clin Pract 2018;6:125-31.

29. Lex KM, Larkin P, Osterbrink J et al. A Pilgrim's JourneyWhen Parkinson's Disease Comes to an End in Nursing Homes. Front Neurol 2018;9:1068.

30. Liefbroer AI, Ganzevoort RR, Olsman E. Addressing

Cite this article as: Paal P, Lorenzl S. Patients with Parkinson's disease need spiritual care. Ann Palliat Med 2020;9(2):144-148. doi: 10.21037/apm.2019.11.24 the spiritual domain in a plural society: What is the best mode of integrating spiritual care into healthcare? Ment Health Relig Cult 2019. doi: 10.1080/13674676.2019.1590806.

31. Balboni TA, Fitchett G, Handzo GF, et al. State of the Science of Spirituality and Palliative Care Research Part II: Screening, Assessment, and Interventions. J Pain Symptom Manage 2017;54:441-53. 